\title{
Competing Practices of Drinking and Power: Alcoholic "Hegemonism" in Southern Ethiopia
}

Jon Abbink

African Studies Center, University of Leiden

\section{Introduction}

When I was about to descend to the Surma lowlands in southern Ethiopia some years ago, I was warned by the people in the last highland village where I stayed: "What? Why do you want to go to these people? They are difficult and violent, and especially when they drink beer the whole day. You will have no food, no bed, nothing. And are you going to drink that beer of them?" I had no good answer then, but I was struck by their emphasizing point of the Surma beer so strongly.

Like violence, alcohol is looked upon as inherently 'problematic': as phenomena of behavior associated with, e.g., addiction, lack of self-control, insolence, unpredictability. But, remarkably, it is often directed by people at some other group, whom they do not like or know well. Alcohol, with its apparent potential for generating trouble, is used as a theme to belittle, patronize and differentiate people, also in Ethiopia in the context of divergent ethnocultural traditions and exposure to state narratives of 'civilization' and governance.

In historical studies of colonial societies in Africa, much attention has been paid to the 'politics of alcohol' as a strategy of control and as an ideological means of group distinction and hierarchy (cf. Akyeampong 1996, Crush \& Ambler 1992, Diduk 1993, Partanen 1986, Siiskonen

- Northeast African Studies (ISSN 0740-9133)

Vol. 4, No. 3 (New Series) 1997, pp. 7-22 
1994). Such politics had, of course, a built-in ambivalent streak: a moral rejection of the local population's alcohol use by (colonial) elites, who especially rejected the indigenous kinds of beer and spirits, and at the same time showing a laissez-faire attitude towards use and abuse, because alcohol $(\mathrm{ab})$ use also allowed those elites to further ground their hegemony in a civilizing narrative and to expand their economic hold on people (e.g., through the import of new kinds). Recent studies have also shown the mutual relation between changing political and economic conditions and ideas and attitudes about indigenous beer and its cultural referents (Colson \& Scudder 1988; Hutchinson 1996:84, 162, 163, 231). Hence, alongside economic mechanisms, we simultaneousily see ideological ones at work. Also, in this article one might start by saying that 'alcohol' is always embedded in relations of valuation: economic but, more important, also political and moral-cultural. Viewed in this light, there is no such thing as a 'history of alcohol in Africa': its existence and use cannot be separated, not even analytically, from its social conditions and constructions.

This article will focts on the case of the Surma in southern Ethiopia, a group of lowland agro-pastoralists, but the problems and dilemmas of changing alcohol use and its valuation are in many respects similar for groups in other parts of Ethiopia and East Africa (for one example, see Rekdal 1996).

While Ethiopia is interesting in that there is no direct colonial legacy (and corresponding 'alcohol policy') with which people have had to deal, also here there are oppositions between several kinds of groups, among them the one between culturally dominant Christian highlanders ${ }^{1}$ and the local, indigenous groups of various ethnic backgrounds.

Southwest Ethiopia was only included in the Ethiopian empire in the late 19 th century and has, in political and economic terms remained quite marginal, though not isolated, since. The many settlers from the North brought (Ethiopian Orthodox) Christianity, state administration, new products and goods, and a different culture. They also founded new villages and small towns. They considered themselves to be culturally superior to the indigenous groups, amongst whom are the Surma, Me'en (both Nilosaharan Surmic-speaking), Dizi and Bench (Omotic-speaking) peoples. This pattern of cultural ranking did not prohibit all kinds of contacts between groups-they maintained economic, social and sexual, and marital relations and partly assimilated-but still, it was maintained until this day. It has been well described in the literature, and historical details will not be elaborated here. What is relevant to note, however, is that this ranking and valuation were also reflected in cultural representations around drinking. Alcohol could thus become emblematic of group distance and 'civilizational' images which people have of each other, even if they are blurred in actual practice.

\section{The Maji Area: Ethnic Interaction and State Authority}

The area under discussion is Maji, a fertile but undeveloped area consisting of a highland range (some $2800 \mathrm{~m}$. at the highest), inhabited by indigenous agriculturists (the Dizi people) and descendants of northern immigrants of mixed origin, and of a surrounding savannah lowland, inhabited by Surma and Me'en agro-pastoralists. The Maji region's economic role in Ethiopia is limited, due to its remoteness, lack of transport facilities (only one precarious dry-season motor road for trucks), lack of natural resources and of export crop production. The only products that are sold for eventual export (going outside the area), but on a very small scale, are coffee, honey, and, for about eight years, gold. Especially, the trade in the latter product has led to more market integration. Gold is panned in the various rivers of this area by both indigenous people (mostly Surma) and by immigrants from the North, who have flocked to one rich location, just outside the Maji area. Here, a new frontier town on the Akobo river (Dima, with some 1,200 inhabitants of very diverse origins) has emerged in the last ten years. The Surma are frequent visitors to this new town and sell their gold to traders with connections in the capital.

Though there are notable differences in ecology, economic activities, language and culture between the highlanders and lowlanders in this area, they are partly dependent on each other for the exchange of food products, utensils, and livestock. There are six towns in this region (ca. 6,500 square kilometers), of which Maji and Tum are the administrative centres. ${ }^{2}$ The Maji region has long been one of the more marginal and neglected areas in Ethiopia. The population of the six villages (some 
9,000 or 10,000 combined) consists largely of state employed officials teachers, administrators, traders, barkeepers, police or militia, and some local people who work as domestics, beer brewers, and builders. Before the inclusion of the Maji area in the Ethiopian state administration in 1898, the local people were politically autonomous. The Dizi people (some 26,000) on the mountain ranges were organized in several chiefdoms, based on agriculture, some cattle-keeping, and forestry. The Surma (about 28,000 people) and $\mathrm{Me}^{\prime}$ en (about 62,000) were autonomous agro-pastoralists in the lowlands with herds of livestock, but were also practicing shifting cultivation of maize and especially sorghum, bee-keeping, and hunting. Up to this day, very few Me'en and Surma have settled in the villages, which has contributed to the maintenance of an ethno-cultural 'divide' along ecological and altitude lines that is typical of southern Ethiopia.

The gradual expansion of village society and the cultural modelsamong them Christianity-brought along by the northerners, many of whom were state representatives, led to a system of cultural ranking in which the customs and traditions of the local people were considered 'uncivilized, and with many of them (starting from the days of the Ethiopian revolution in 1974) even declared to be 'harmful customs' (Amharic: yegodjee bahil). Next to (the lack of) clothing, certain rituals, body scarifications, and certain food habits, the consumption of some types of alcohol was one of these.

Another party has also presented itself in the local 'moral discourse' on alcohol: the-inevitable-missionaries. They are of a Protestant denomination (both with foreign and Ethiopian background) and have since 1991 one settlement in the Surma area. They reject all forms of alcohol, including the Surma gèso beer. Even the socio-economic role of gèso parties in the agricultural process is devalued, rejected, and no Surma or other local person who drinks alcohol may work for them. (This has limited their appeal so far, and I will not pursue the influence of this factor here.)

\section{Alcoholic Beverages in Southern Ethiopia}

Among the indigenous people in the Maji area (the Me'en, Dizi and Surma), the only alcoholic drink before the arrival of the northerners some 100 years ago was the local maize-sorghum beer. There are reports that Me'en and Surma people had their own honey-wine, called boké, somewhat similar to tädj, but it is difficult to say whether it was made independently or derived from the example of $t \ddot{a} d j$.

Especially in the second half of the twentieth century, the alcoholic drinks from the highland culture reached them. These various, for them new, beverages were thus spread here (and in Ethiopia in general) by the processes of group contact and migration of mostly Christian highlanders in the country. The alcoholic drinks in the area under discussion may be categorized into two kinds:

1. 'Those considered the 'social' drinks, harmless ones consumed mainly during communal and family gatherings. These are called t'alla and $t^{\prime} \ddot{a} d j$ (with their Amharic terms; there are no good English words). They are, so to speak, the 'good ones': unproblematic and meant for socializing. The t'älla beer (in the northern Tigray region it is called sua) is of low alcohol content (circa 6 to 7 percent $^{3}$ ) and has a somewhat 'smoky' taste. It is made by women. The production of this beet demands considerable skills and a good result is a source of pride and admiration. It takes at least one week to produce both drinks, not counting the gathering of the ingredients. This beer is never produced or sold in bars (although some restaurants in Addis Ababa have recently started to serve it). It is purely a beverage for family occasions and (Christian) religious days, and is very popular and highly valued. ${ }^{4} T^{\text {'älla }}$ is not considered a beer on which people get drunk.

The t'adj is the typical Ethiopian honey wine, made of water, honey (or sugar in the cruder blends), and crushed buck thorn (gesho, or Rhamnus prinoides L'Hérit.) leaves as a fermenting agent. It used to be a drink for the upper classes in the past but is now widespread in all walks of life. It is a drink for secular holidays and weddings, and is served in bars and small cafe's all over Ethiopia 5 (These places owe their name to the drink: $t^{\prime} \ddot{a} d j$-bet, house of the $t^{\prime} \ddot{a} d j$. As can be expected, there are no t'älla bets). The alcohol content of t'äj can vary from 8 to 14 percent. ${ }^{6}$ It has become the prime drink of the common Ethiopians not only in the towns, but also in the southern countryside bars. While traditionally it was neither a beer to get drunk on, t'ädj (often sold in the bars in a diluted form, and not on the basis of honey but of sugar) has now lost some of its 'prestige': the $t$ 'ädj-bets are places were people do tend to drink and get drunk and spend a fair amount of money. On market days in the 
South, a significant portion of the cash that the rural sellers in the market have acquired from village dwellers for their foodstuffs and other products is converted back again into the village economy.

2. The second genre of alcohol is that of the 'local beers,' subsumed under the local Amharic name borde. These are made from fermented maize, sorghum and sometimes barley (or a mixture of them) and are typical for south-western Ethiopia. It is a thick and heavy beer, almost a fluid porridge, which can serve as a full meal in itself. The Surma term for their beer is gèso. 7 The production of these traditional beers is always by women and is a laborious process, taking from eight to ten days. The alcohol content has not been measured scientifically, but is estimated to be around six to seven percent.

There are four kinds of Surma gèso, according to quality and alcoholic content: 1. the jendáy; a warm, very fine filtered beer, and the strongest (most alcoholic) variety; 2. nyanna gid'anga, the second in alcohol content; 3 . the challa, and 4 . the b'oru. These traditional beers have low prestige in the eyes of the village people and of the people connected with the state administration. The citation with which this article opened reflects this disdain. ${ }^{8}$ This attitude implies that 'civilized' people (i.e. those in the village and connected with the wider Ethiopian culture) should not drink this beer. Only when on a long walking trip in the countryside between villages, e.g., for purposes of trading, one can drink them, because there is often a lack on food on the road. Here again is the ambivalent attitude towards these 'native beers': drunk when there is no choice, but ridiculed when one is back in town.

Nevertheless, for the Surma the consumption of gèso was a social activity par excellence, and perhaps an example of what Mary Douglas would call 'constructive drinking' (Douglas 1987). In his research on the Kenyan Iteso, Ivan Karp also interpreted their communal beer-drinking as a symbolic activity that expressed an ideal-though not the practiceof ". . . diffuse solidarity and unencumbered sociability." (Karp 1980:84). (Although it simultaneously carried associations of danger, through the fear of poisoning and sorcery, unlike the Surma case). More interesting, however, than pursuing this slightly neo-functionalist line of argument, is to look at how 'hegemonic relations' between groups are partly expressed though references to alcohol.

3. To pursue this, the third and much more problematic drink should be mentioned. It is the local araqe, or katikala, a homemade distilled drink originating in the highland area, and now also found in the Maji area (See Ethiopian Nutrition Institute 1980: 139 for a traditional recipe). It is made on the basis of germinated grains, especially maize (Zea mays) or finger millet (Eleusine coracana), sometimes mixed with wheat (Hordeum vulgare) and with added agents like sugar and the leaf kosso (Hagenia abyssinica). It can have an alcohol content in the range of 30 to almost 50 percent. 9 There are also imported and factory-produced varieties, but these are not considered as good as the homemade ones. Other strong drinks available in some bars are foreign-imported whisky and Ethiopian-produced gin, ouzo, and cognac. They are not popular among the rural people in Maji but again only among the elite (see note 4). Araqé and katikala are more expensive than any beer, and seen as haylenya, i.e. strong and challenging to the drinker. The best araqés are the ones are reputed to be the mar araqé (made on a basis of honey) from the Gojjam region or from the Debre Berhan area. While the real aragé from these areas is seen as a real treat and to be consumed with care and enjoyment, the related katikala, is, however, seen in a more ambivalent way. Even though it is accepted and widespread among the highland societies (in the countryside), it has the aura of being dangerous and unreliable, and of being a sure and quick way to drunkenness and a cause of violent behavior. In contrast to t'älla and t'ädj, it is a 'bad drink', moreover, considered by the people themselves to be highly addictive: an example of destructive not constructive drinking. Katikala is, nevertheless, popular all over the Ethiopian countryside, and its alcohol content there can be estimated at some 35 to 40 percent.

Its production requires some skills-possessed by highland Christian women-and special equipment. The Surma and other people of the Maji countryside do not know how to produce it, and do not have sugar. But they all buy katikala in the village bars and transport it to their home areas (often many hours' walk) in bottles owned by the village producers.

\section{Economic Aspects}

For an estimate of economic aspects of the production of alcoholic drinks in this area of Ethiopia, it is important to note that there is still no problem of land and firewood scarcity in the Maji area: all farmers of 
any of the groups mentioned can get a reasonably good and large enough piece of land for cultivation. Even returning soldiers from former president Mengistu's crumbled army in 1991-92 could easily start farming in the Maji area, which thus compared favorably to most other areas of Ethiopia. Surma and other groups maintain the fertility of their land by methods of rotating crops and of shifting cultivation. However, poverty is rampant in the area, and due to the pressure of the state for tax payments in cash, there is a growing demand for money. This is a relatively recent development (for approximately thirty years): up to the mid1960 s, tribute was often paid in kind (cattle, grain, livestock, honey, etc.) or in labor services. In the later years of the Mengistu-regime (19751991), the taxes significantly increased, and while they were abolished for a few years in 1991-1993, they are now back again in full force under the new federal government. To be able to pay them the local people often sold productive assets. The need for cash to pay the taxes wasand is-often met with the proceeds from the sale of livestock, which impaired people's economic prospects. In addition, people (especially the Me'en) used the proceeds of coffee and honey sales. The Surma, due to their wealth in livestock, could easily pay the taxes, which they did in Haile Selassie's time (up to 1969), but at present, the state administration has not been able to enforce taxation among them. There is yet no strong pressure to find alternative sources of income outside the agricultural or agro-pastoral economy.

Since the 1940s when economic and market integration of the Ethiopian Southwest started, there has been an expansion of beer-brewing and alcohol sale as a business on which the producers can sustain themselves, but only in the six market villages. Beer-brewing was never-and is still not-a source of cash for any people outside the villages. Among the Surma, in virtually every household, the women now and then make géso, but for other economic (for labor on the family fields) and ritual reasons. This has the twofold effect that: a) there is not enough demand outside the market centers (the villages) because households are 'self-sufficient' most of the time; and that: b) the non-commercial production and consumption of local beer (for limited social or ritual reasons) within Surma society itself dominates. One could say that beer is still largely contained within a non-monetized social context of reciprocity and exchange. Transport problems also mitigate against the commercialization of local beer. The carrying of the big clay beer jugs to places of demand is virtually impossible. The few smaller calabashes that are brought to the markets by some Dizi women (never Surma) yield on average no more than about 34 to 40 Ethiopian birr profit per market day, which is about U.S. \$4. In any case, Surma (and $\mathrm{Me}$ 'en and Dizi) beer-brewing has not yetbecome a commercial business that could provide a source of income for women (who are always the brewers of the beer). The picture of women doing the beer-brewing and producing the other drinks and thus controlling the production side is similar to that in many other East African countries. However, the big difference in this Ethiopian situation is that the alcohol sales in the market villages (where thousands of people of various groups gather twice a week) are controlled by village women who are descendants from earlier migrants from the highland North, and not by those from indigenous groups of the area. Local Surma and Me'en women own no bars. In the town of Maji (with a 1994 population of 1,617 , see: Central Statistical Authority 1996: 22), there are at least twelve t'ädj-bets and two bordé (local sorghum beer) cafe's. Whether the bars have supply on a particular day can easily be recognized by a tree trunk or stool placed outside, on the path, on which an empty can (bordé), a small cup (katikala) or a bottle ( $\left.t^{\prime} \ddot{a} d j\right)$ is put. In Maji village, only one of the bars for bordé is run by a Dizi woman and is patronized by Dizi people; the rest by others, mostly of northern of mixed descent (Although, of course, these people are now also locals and no longer 'immigrants'). The clientele they serve is from the surrounding countryside, the population of which is estimated at about 20,000 , perhaps one-third of which is adult (21 and older). Every bar is full the whole day during market days (twice a week), and the profits can be substantial. It is an economy of drinking which thrives on the clientele of the local countryside population, but which nevertheless remains confined to the villages in the area and does not spread beyond it.

\section{Social Aspects}

What t'alla and, to a lesser extent, t'ädj are for the Amhara and other highlanders, gèso is for the Surma people (perhaps even in a deeper sense): a social drink, the occasion calling for coming together, for commensality. 
Gèso-drinking in itself is a sign of relaxation of social relations, of intentions toward peace, and of reconciliation: in short, expressive of sociability. It is always drunk in a group and in public, and not-like foodconsumed in silence and solitude in the family hut. It is always drunk while seated, never when standing. Men and women also drink it together.

Its most frequent-and obligatory-use is during agricultural work parties (called gasa). The Surma do not have plough agriculture but hoe agriculture, and such collective work parties are then an absolute prerequisite, especially in the heavy stages of clearing a field, and later harvesting. Geso has also a high nutritional value and is usually taken as the only lunch meal. Any person, male or female, who has decided to clear and cultivate a piece of land has beer prepared, spreads the word, and can count on a big turn-out for the work in the fields. As elsewhere in peasant societies in rural Africa, where there is no beer, there is no work. The work of a Surma gasa work party starts about 8:30 a.m. and goes on until about 10:00 or 10:30. Then there is a break for drinking gèso, after which one may go on until 3:00 in the afternoon, whereupon the remaining beer is drunk. In the field, there is often a hut of the cultivator of the field where his mother or wife (and in the case of a female, her mother or sisters) already drink some of the beer with other women and elders before the break. The ritual leader of the Surma (the komoru) is always invited for any work party in the nearby surroundings. The women sit together, chat and joke and let the men do the work, impervious to calls of the men before a substantial amount of work has been done. Women often serve themselves before serving the men. They also decide who gets any gèso and when.

The beer during a work party thus implicitly stands for the recognition of the mutual dependence of households, especially of and through women, who organize the work parties and make the beer (The women also do most of the weeding and other work between the work of preparing the field and of harvesting). Even though there may be conflicts and arguments during the consumption of the gèso beer (among the Surma certainly), it always brings people together.

It is noteworthy that in the other main branch of Surma economic life, the herding of livestock, the beer was traditionally not drunk. The Surma have cattle camps which are located at some distance (about a day's walk) from their villages and hamlets, and while the young men brought food from their relatives there, they never took gèso beer. We see that the beer is solidly associated, both economically and symbolically, with agricultural, i.e. 'female' activities. Instead, the males in the cattle camps drank blood and milk from their animals.

Hence, the gesso beer can be seen, indeed, as one of the fuels of the rural economy, but not to get cash. Only in the last three to four years, one can note that some women started to sell some of the gèso in their own compound, but on a very irregular basis and with a very marginal profit. Often, when beer is left from the above-mentioned work parties, the women may decide to sell it to other people.

The gèso-beer is drunk at all festive occasions, the main ones being a name-giving, the initiation of an age-group, the conclusion of a day of ceremonial dueling, the inauguration of a new field for crop-cultivation, and last, but not least, a wedding ceremony. This points to its use as a ritual drink, e.g. at a field inauguration, in some ceremonies of initiation and also at a reconciliation (The same is true for the local sholu beer among the related Me'en people). For instance, when a dispute is mediated, the mediators, who are of another clan or family group have to bring local beer to seal the reconciliation. The two opponents have to drink it cheek to cheek from one calabash (cf. a similar custom among the Iraqw: Rekdal 1996: 367). This is never done with katikala.

However, at several important internal-political occasions in Surma society, such as public debates (see Abbink 1997 for a case-study), divination from intestines, a funeral, and during homicide compensation talks, no beer is ever drunk. Therefore, one can note many socio-cultural restrictions on the actual use of the gèso-beer, which refutes the idea of the villagers that it was drunk 'all day by almost everybody'.

The katikala, however, is changing the picture, due to its extraneous origin and functions. It can be noted that in the period before the import of new alcoholic drinks, there were no socially (and statistically) significant numbers of drunks in the Surma or Me'en communities. All informants from the Surma, Me'en and Dizi agree in the statement that constant problems of drunkenness 10 (and even of liver-disease) started in the last fifteen to twenty years (for the Surma even much more recent: only since around 1989) in their societies, when katikala production and consumption increased markedly. This may be a biased view, but at 
least for the Surma people the majority of whom came only into close contact with the highland village society in the last decade, this observation finds confirmation in the records of the local health clinic in Maj1 over the past decades.

The larger incidence of physical and social problems related to alcohol abuse is most likely a result of the increased consumption of katikala, both by the Surma and by the village people who sell it to them, but also blame them for drinking too fast and too much. This brings us back to the different, and partly paradoxical, valuations of alcohol and its use among the local population groups of the Maji area.

\section{The 'Statements' of Gèso and of Katikala and Their Cultural-Political Dimension}

Katikala, the strong and dangerous beverage, is becoming the new 'status drink' among the indigenous people in the Maji area, especially the Surma. Why? People state they simply like it because of its physical effect: giving (the illusion of) warmth and strength, at least initially. They often take it before traveling, which usually means a long walking trip back to their home area. Undotibtedly the other familiar reasons apply also here: suppressing hunger, forgetting immediate worries, group pressure, and so on. There are also other reasons. First of all, katikala is expensive, and thus a drink taken and given as a present by the wealthier people to important friends and guests. To give a good botthe of katikala is a sign of generosity and/or wealth, and is highly esteemed by the receiver. Secondly, in local rural society, it is a drink located outside familiar social categories, originating from the sphere of trade objects and commerce. It is neutral, objectified. This contrasts markedly with the status of the bordé-beer, long the only local alcoholic drink, which was (and is) embedded in patterns of labor exchange, balanced reciprocity and ritual relations. As we saw, in Surma society, the gèso-beer was the 'compensation' for participation in agricultural work parties. This beer was, therefore, never sold. As was said above, the Surma have no land scarcity, only labor scarcity. Moreover, as we saw, the beer was a medium of conciliation.
Nevertheless, the increased acceptance of katikala, hence, also reflects an expanding monetization and market integration of the Surma economy into the regional economic framework. In this sense, the introduction of this hard liquor - the drinking of which has become a nationwide habit predictably connected to notions of toughness and masculinity-has signified the coming of modernity.

In the peripheral multi-ethnic situation in the Maji area, we see an ambivalent though clear pattern of 'alcoholic hegemonism.' The culturally dominant villagers want to have the best of both worlds. Their types of alcoholic drinks, so to say, are 'the best, and they think they knowat least most of them-how to use and not abuse them, and the local people (the Surma, Dizi and Me'en) are 'still caught' in their traditional drinking habits of their local bordé beer and are subjected to the harsh reign of katikala, which they cannot handle and thus tends to create trouble. That they themselves (the villagers and state-connected people) have introduced it and often even go to the Surma and Me'en areas to try and sell it, is not mentioned, or at least does not make them feel in any way responsible for such trouble. Furthermore, they have succeeded in spreading the consumption of these new alcoholic drinks ( $t^{\prime} a d j$ and katikala) - to derive substantial economic gain from it. Their attitude is, as such, an unwitting part of the expanding domain of the state and of the wider Ethiopian society, which must devaluate local traditions, including local types of alcohol like the 'crude gèso beer.' Although gèsodrinking is, in this view, tolerated as 'Surma culture,' it is looked down upon and ridiculed, and moreover seen as a source of alcoholism. For instance, Surma inter-personal violence is often explained by a reference to ". . their habit of always drinking too much beer." When villagers (Amhara and other) see the Surma and Me'en drink there they also say that "too much money is thrown away again by these people," suggesting that they-in contrast to the speakers-cannot drink in a controlled, civilized manner.

But Surma (and Me'en) beer drinking is not a social pathology, at least not more than among any other group in the Maji area. What the villagers do when they speak with disdain of the gèso beer is first and foremost to make a statement about difference, about the way of life and the 'uncontrolled' and perhaps the solitary group behavior of the Surma. A social pathology can, however, emerge after the introduction by the katikala beverage itself, because of a new form of drunkenness. 
For the Surma, katikala has indeed no traditional spiritual or social meaning, like gèso has. It is still unclear in what terms they will ultimately incorporate it into their drinking culture. While it is now indeed a prestige object given and shared between people as a sign of respect, wealth, or virility, it may be that people (especially women) will not remain impervious to its negative side-effects, among them the more frequent and more serious form of drunkenness, and emerging competition for cash within the household.

At the same time, the increased role of katikala leaves the traditional social role of the gèso beer in the Surma social life yet unaffected: it is not (yet) significantly commercialized, and it will continue to function as a socializing agent and as compensation for agricultural work. The gèso is also associated with food, life and procreation, while katikala is not: it has no 'positive' qualities yet. Ambivalence is a core issue here. At present, katikala tends to be used mostly in social contexts that are 'structurally' located outside the local moral economy. That means, never in work parties or at rituals, but only at informal meetings of male friends, in small groups visiting the villages, and also more in the cattle camps. Finally, one other example, encapsulating the ambivalent connections between alcohol, power and cultural dominance, is that of the Surma Local Council. This Council is a newly formed (1994) supposedly selfgoverning body of about eleven, mostly young, Surma, assisted by some other Ethiopians sent by the regional government. It was meant as a prime locus of constructive government influence in Surma society. The cash resources of the Council members (who are government-salaried, which is a new thing for the Surma) are not insignificant, and in 199596 (the time of fieldwork) they brought in the katikala from Maji village almost daily. The fact of Surma 'drunkenness,' which has become a frequent phenomenon within the Council premises (also more and more in village bars), is explained by many northerners as being another example of their still 'uncivilized' or 'underdeveloped' social life, which will be remedied with time. In their eyes, the project of politically and, especially, culturally integrating the Surma is not yet completed. The paradox that, in the above instance, the state's presence may have delayed this process is conveniently ignored.

\section{Notes}

1. Muslims are a tiny minority in this area and usually do not drink alcohol.

2. Since 1993 divided into three districts (i.e., woredas) along 'ethnic' lines: Dizi, Me'en, and Surma.

3. In the research of Belachew Desta (1977: 67) an average of 6.07 ethyl alcohol percentage was found, within a range of 5.65 to 6.56 .

4. The imported beer or the bottled beer from factories elsewhere in Ethiopia is scarce and only available in some bars. It is drunk by the political, educational and civil servant elite only.

5. When the drink is not yet fermented it is called birs, a kind of honey lemonade.

6. Desta (1977: 67) gives an average alcohol percentage of 13.36 (range: 13.18 to 13.73$)$.

7. The Dizi term is muugu, the Me'en term sholu. They refer to the same thick and strong brewed sorghum-maize beer.

8. However, somewhat similar beets are found in the north and central highlands as well, among them: korefe in the Gondar area (made from batley), and shaméta of the Gurage area (which is, however, lighter in alcohol content, made from toasted barley). A non-fermented grain drink is buk' $r$, in the north Shewa, Gondar and Gojjam areas, which has virtually no alcoholic content but again is a drink on the basis of barley, and drunk during religious holidays. They are not drunk as food, like the bordé in southwest Ethiopia.

9. In B. Desta's research, the t'erra-aragé and the dagim araqe the average alcohol percentages found were respectively: 34.09 and 46.6 (Desta 1977: 67).

10. In the Surma language, there is no concept of 'drunkenness', only of 'being excited' or 'agitated' due to alcohol use.

\section{References}

Abbink, Jon. Forthcoming. "Violence and Political Discourse among the Chai Suri." In Surmic Languages and Cultures, edited by Gerrit J. Dimmendaal. Cologne: R. Köppe Verlag.

Akyeampong, Emmanuel K. 1996. Drink, Power and Cultural Change: A Social History of Alcohol in Ghana, c. 1800 to Recent Times. Oxford: James Curtey; Portsmouth, NH: Heinemann.

Central Statistical Authority, Ethiopia. 1996. The 1994 Population and Housing Census of Ethiopia Results for Southern Nations, Nationalities and Peoples' Region. Volume I. Statistical Report, Part I. Addis Ababa: CSA.

Colson, Elisabeth, and Thayer Scudder. 1988. For Prayer and Profit. The Ritual, Economic and Social Importance of Beer in Gwembe District, Zambia, 19591982. Stanford, CA.: Stanford University Press.

Crush, Jonathan, and Charles Ambler. 1992. Liquor and Labor in Southern Africa. Athens, Ohio: Ohio University Press; Pietermaritzburg: University of Natal Press. 
Desta, Belachew. 1977. "A Survey of the Alcoholic Content of Traditional Beverages." Ethiopian Medical Journal 15: 65-68.

Diduk, Susan. 1993. "European Alcohol, History and the State in Cameroon." African Studies Review 36, no. 1: 1-42.

Douglas, Mary, ed. 1987. Construative Drinking: Perspectives on Drink from Anthropology. Cambridge: Cambridge University Press; Paris: Editions de la Maison des Sciences de l'Homme.

Ethiopian Nutrition Institute. 1980. Ethiopian Traditional Recipes. Addis Ababa: ENI.

Hutchinson, Sharon E. 1996. Nuer Dilemmas. Coping with Money, War and the State.

Karp, Ivan. 1980 "Beer Drinking and Social Experience in an African Society: An Essay in Formal Sociology." In Explorations in African Systems of Thought, edited by Ivan Katp and Charles S. Bird, 83-119. Bloomington: Indiana University Press.

Partanen, Juha. 1991. Sociability and Intoxication. Alcohol and Drinking in Kenya, Africa and the Modern World. Helsinki: Finnish Foundation for Alcohol Studies.

Rekdal, Ole B. 1996. "Money, Milk and Sorghum Beer: Change and Continuity among the Iraqw of Tanzania." Africa 66: 367-85.

Siiskonen, Harri. 1994. "Namibia and the Heritage of Colonial Alcohol Policy." Nordic Journal of African Studies 3, no. 1: 77-87. 